
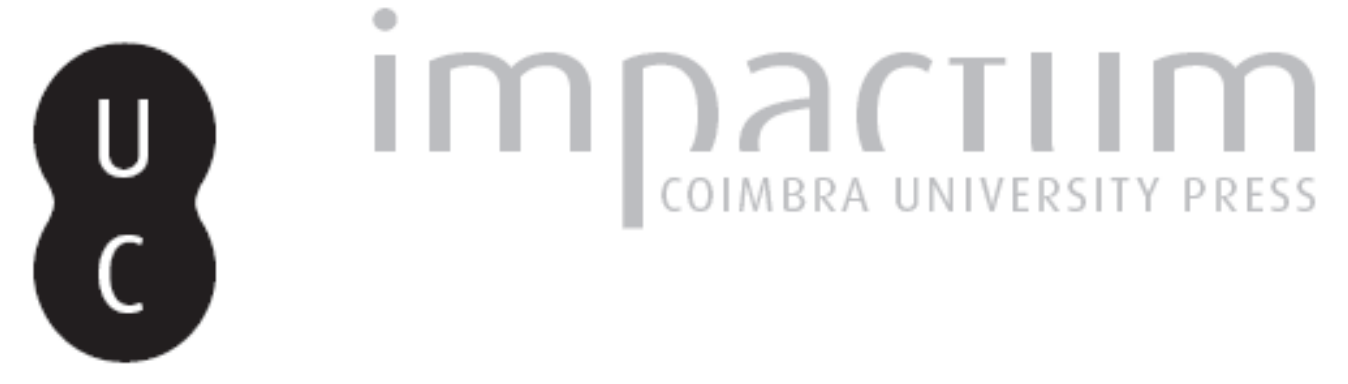

\title{
Quarenta anos a ensinar italiano
}

\section{Autor(es): $\quad$ Mea, Giuseppe}

Publicado por: Imprensa da Universidade de Coimbra

URL persistente:

URI:http://hdl.handle.net/10316.2/42518

DOI:

DOl:https://doi.org/10.14195/0870-8584_5_5

Accessed : $\quad$ 26-Apr-2023 13:38:23

A navegação consulta e descarregamento dos títulos inseridos nas Bibliotecas Digitais UC Digitalis, UC Pombalina e UC Impactum, pressupõem a aceitação plena e sem reservas dos Termos e Condições de Uso destas Bibliotecas Digitais, disponíveis em https://digitalis.uc.pt/pt-pt/termos.

Conforme exposto nos referidos Termos e Condições de Uso, o descarregamento de títulos de acesso restrito requer uma licença válida de autorização devendo o utilizador aceder ao(s) documento(s) a partir de um endereço de IP da instituição detentora da supramencionada licença.

Ao utilizador é apenas permitido o descarregamento para uso pessoal, pelo que o emprego do(s) título(s) descarregado(s) para outro fim, designadamente comercial, carece de autorização do respetivo autor ou editor da obra.

Na medida em que todas as obras da UC Digitalis se encontram protegidas pelo Código do Direito de Autor e Direitos Conexos e demais legislação aplicável, toda a cópia, parcial ou total, deste documento, nos casos em que é legalmente admitida, deverá conter ou fazer-se acompanhar por este aviso.

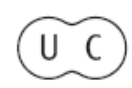




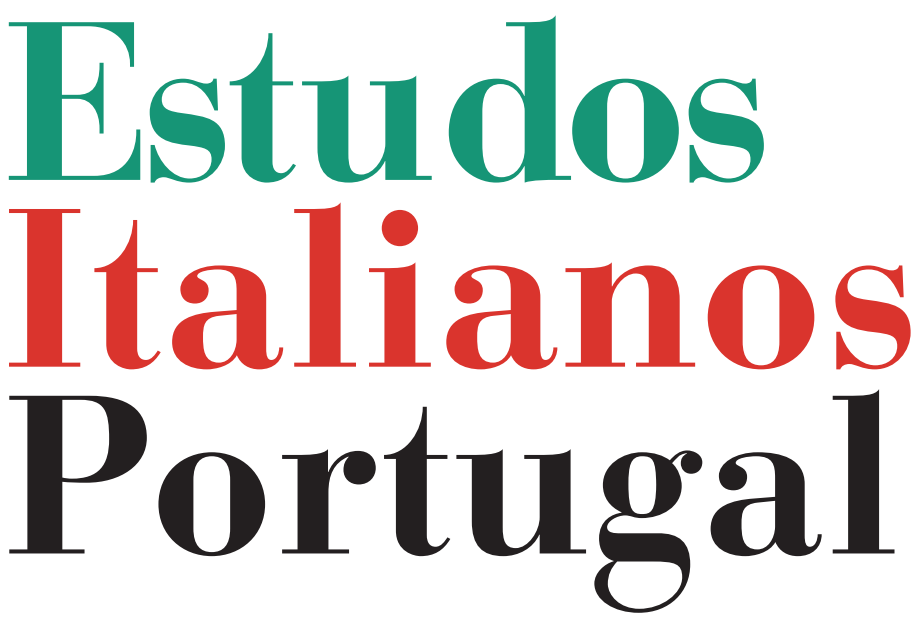

Instituto

Italiano

de Cultura

de Lisboa

Nova Série

$\mathrm{N}^{\mathbf{0}} 5$ 


\title{
PORTO. UNIVERSIDADE DO PORTO E OUTRAS INSTITUIÇÕES
}

\author{
QUARENTA ANOS A ENSINAR ITALIANO \\ Giuseppe MeA*
}

Quando sono arrivato a Porto nel 1971, fresco di laurea e con una borsa di studio di lunga durata, sono stato invitato a tenere dei corsi di lingua italiana presso la sezione staccata dell'Istituto Italiano di Cultura, nel locale dove funzionava - e tuttora funziona - il Consolato Onorario d'Italia.

Nelle aule ho trovato ancora i banchi e le lavagne che erano appartenute alla scuola elementare italiana a Porto, soppressa nella seconda metà degli anni '50. Questa scuola, con un centinaio di allievi, e che seguiva l'ordinamento scolastico italiano (5 anni invece dei 4 portoghesi), era frequentata soprattutto dai figli della media borghesia portuense e dai figli delle poche famiglie italiane residenti a Porto (i Dolce, i Di Nunzio, i Flaminio, gli America e pochi altri).

La colonna dell'Istituto Italiano era la Sig.na Annamaria Morelli, già maestra della scuola elementare, che per più di quattro decenni, ha insegnato la lingua italiana a per lo meno due generazioni di portuensi.

Oltre all'Istituto Italiano, frequentato da una cinquantina di persone, l'italiano, agli inizi degli anni '70, era insegnato

* Leitor da Faculdade de Letras da Universidade do Porto de 1971 a 2008, ensinou também na Universidade do Minho e na Universidade Católica do Porto. Director Didáctico dos Cursos da Câmara de Comércio Italiana no Porto. Ocupou cargos diplomáticos. Além de tradutor, é autor dos dicionários Italiano-Português e Português-Italiano, Porto Editora/Zingarelli. Acaba de publicar Gramática prática de Italiano para lusófonos. 
anche al Conservatorio di Musica, per gli studenti che seguivano il corso di canto. Il professore era Don Ângelo Ferreira, un sacerdote che aveva fatto gli studi teologici a Roma.

Nell'agosto del 1972, è creato presso la Facoltà di Lettere, il Lettorato Italiano. Nei primi anni la materia di studio era Lingua e Letteratura Italiana, un esame complementare (da scegliere in alternativa a Lingua e Letteratura Spagnola) del $3^{\circ}$ anno del corso di laurea in "Românicas". Passati alcuni anni, questa materia è stata scissa in due: Lingua Italiana e Letteratura Italiana, sempre come esami complementari, con iscrizioni alterne. In alcuni anni la disciplina di Lingua Italiana (con punte anche di 70/80 studenti) aveva più iscritti, in altri avveniva il contrario (con punte anche di 50 iscritti).

Agli inizi degli anni '80, all'Istituto Italiano si è verificato un salto di quantità, anche grazie ad una ristrutturazione dei corsi, ad un cambio generazionale del corpo docente e dirigente e ad un aumento del potere d'acquisto dei portoghesi. Dai 50/60 iscritti degli anni '70 si è passati al raddoppio di tale numero, con punte che sono arrivate, in alcuni anni, fino a 140 unità.

A Porto l'Istituto Italiano di Cultura e il Lettorato Italiano presso la Facoltà di Lettere continuavano ad essere $\mathrm{i}$ centri più importanti di irradiazione della lingua e cultura italiana del Portogallo del Nord. Nel 1994, a causa di una ristrutturazione degli Istituti Italiani di Cultura all'estero, promossa dal Ministero degli Affari Esteri Italiano, da cui dipendevano, è stata soppressa la Sezione Staccata di Porto. Affinché non vi fosse una dispersione degli iscritti - un centinaio - la Delegazione di Porto della Camera di Commercio Italiana in Portogallo si è presa carico dei corsi, mantenendo il corpo docente, la linea didattica, i locali e i suppellettili tutti. Dal 1994 ad ora, sotto la direzione della Camera di Commercio Italiana, la media annuale degli iscritti si è mantenuta inalterata. 
A partire dai primi anni del 2000, a Porto si è notato un fenomeno, fino ad allora inedito. Alcuni istituti privati di lingue hanno incluso nella loro gamma d'offerta anche la lingua italiana. Così ora a Porto ce ne sono per lo meno 5/6 che offrono l'insegnamento della lingua italiana. Dal 2007 funzionano dei corsi per bambini dai 3 ai 13 anni di età, che sono divisi in quattro livelli, organizzati dall'Associazione Socio-Culturale Italiana del Portogallo, presso il Consolato di Porto.

Nel 2008, il lettore di italiano presso la Facoltà di Lettere (dove ha insegnato ininterrottamente dal 1972) è andato in pensione e non è stato sostituito. Quando avremo di nuovo l'insegnamento della Lingua e Letteratura Italiana alla Facoltà di Lettere di Porto?

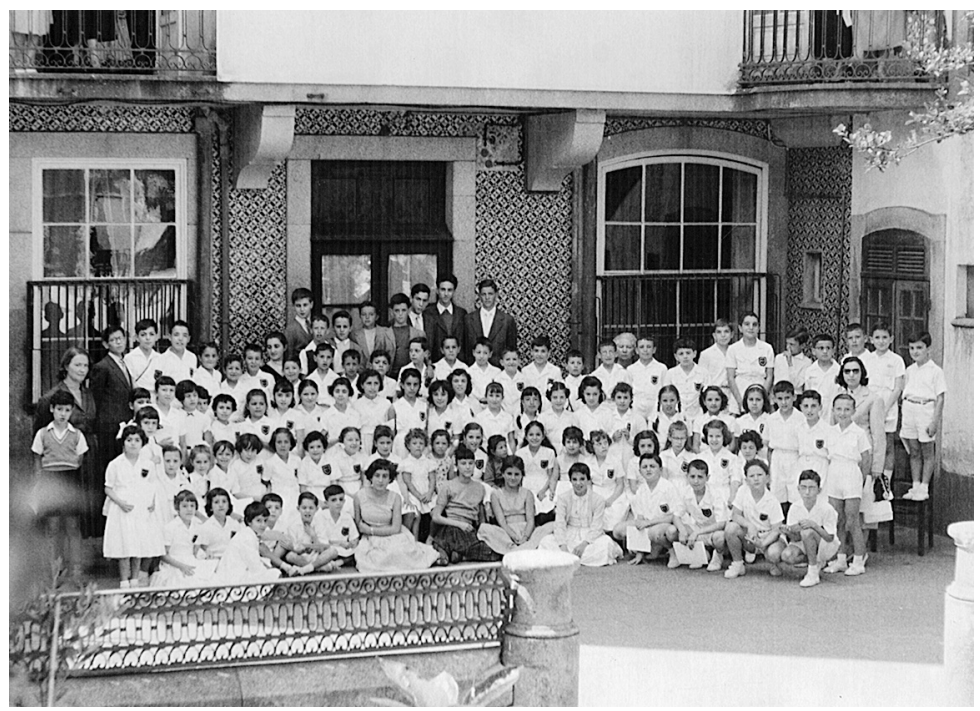

Gli allievi della scuola elementare italiana di Porto. Anno 1956 